Atatürk Üniv. Diş Hek. Fak. Derg.

] Dent Fac Atatürk Uni

Cilt:29, Sayı:3, Yıl: 2019, Sayfa, 519-525

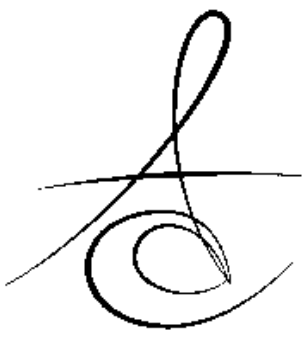

\title{
DİŞ HEKİMLİĞİNDE KULLANILAN FİBER POST SİSTEMLERİ
}

\author{
DENTAL FIBER POST SYSTEMS
}

\section{Dr. Öğr. Üyesi Zuhal GöRÜş* \\ Dr. Ozan Erdost EVRAN ${ }^{* * *}$}

\author{
Doç. Dr. Ayşe MEŞE** \\ Dr. Merve TOKGÖZ ÇETÍNDAĞ ${ }^{* * * *}$
}

Makale Kodu/Article code: 3148

Makale Gönderilme tarihi: 23.11.2016

Kabul Tarihi: 20.01.2017

\section{öz}

Diş hekimliğinde dental rehabilitasyonların estetik per formansı için zamana duyulan ihtiyaç önemli konulardan biri olduğu gibi , uygulanan sistemin dayanıkıılığı, güvenilirliği ve basitliği çok daha fazla önem taşır. Fiber post-kor sistemleri hekime uygulamaya hazır halde sunulmaktadır. Fiber postlar dentine benzer yapısından dolayı hem hastaların hem de hekimlerin beklentilerini karş ılamaktadır. Fiber postların dentine benzer fiziksel davranışları oklüzal yükler altında oluşan stresi diş dokularına zarar vermeksizin yönlen dirmesine imkan tanımaktadır . Buna ek olarak adeziv teknolojisindeki gelişmeler fiber post -kor restorasyonun klinik başarısında gözle görülür bir ilerleme sağlamıştır. Bu derlemede günümüzde diş hekimliğinde kullanılan fiber post sistemleri anlatılmıştır.

Anahtar Kelimeler: Fiber post, adeziv, post-core sistemleri

\section{ABSTRACT}

The time needed for esthetic performance of dental rehabilitations have become an important issue in dentistry; however, the strength, reliability and simplicity of the system in the use are even more important. Glass post-core systems are ready to use. On the hands, dentin-like appearence and structure of the posts meet the expectations of both patients and practitioners. The physical behavior of the glass posts similar dentin navigates the stresses generated beneath the occlusal loads without being detrimental to the tooth structures. Moreover, the development of adhesive technology led to a remarkable progress in the clinical success of glass post-core restorations. This article describes currently used fiber post systems.

Key Words: Fiber post, adhesive, post-core systems

\section{GİRİş}

Endodontik tedavi görmüş dişler giriş kavitesi hazırlanırken pulpa odası tavanının kaybı, kanal anatomisinin değiştirilmesi ve vital pulpadan sağlanan nem eksikliği gibi nedenlerle yapıları fiziksel olarak zayıflamakta ve yüksek kırılganlık riski taşımaktadırlar.

Endodontik tedavi görmüş dişlerde dentin kanalcıklarının mineralizasyonu ve dehidrasyonu sonucunda zamanla dentin esnekliğinde azalma meydana gelmektedir. Dentin kırılganlığı artarken, korunmamış tüberküllerde ve servikal bölgede kırılmalar ortaya çıkmaktadır. ${ }^{1,2}$
Travma, restorasyonlar, ikincil çürükler ve endodontik kaviteler nedeniyle aşırı madde kaybına uğramış dişlerin restorasyonu diş hekimliğinde önemli sorunlar teşkil etmektedir. Yapılan restorasyonların uzun vade başarısı için geriye kalan diş dokusunun korunması ve tutuculuğun sağlanması gerekmektedir. $\mathrm{Bu}$ restorasyonlara tutuculuk ve desteklik sağlamak amacıyla kök kanalından destek alınarak post ve kor sistemleri kullanılmaktadır. Post-kor restorasyonlarda, kök kanalı içerisinde yer alan ve kök kanalının 2/3'üne kadar uzanan kısma "post", kaybedilen dentin dokusunun yerine hazırlanan ve koronalde yer alan kısma "kor" adı verilir. . $^{3,4}$

\footnotetext{
*Harran Üniversitesi Diş Hekimliği Fakültesi, Protetik Diş Tedavisi AD, Diyarbakır

** Dicle Üniversitesi Diş Hekimliği Fakültesi, Protetik Diş Tedavisi AD, Diyarbakır

*** Diş İzmir Ağız ve Diş Sağlı̆ı Merkezi, İzmir

**** Diyarbakır Ağız ve Diş Sağlığı Hastanesi, Diyarbakır
} 
Endodontik olarak tedavi görmüş dişlerin uzun dönem başarısı dişi destekleyen dokuların sağlğını koruyan kaliteli bir restorasyona bağlıdır. Endodontik tedavi görmüş bir dişin restore edilebilmesi için:

1. İyi bir apikal kapanmanın sağlanmış olması,

2. Basınç uygulandığında hassasiyet olmaması,

3. Eksuda olmaması,

4. Mobilite olmaması,

5. Periodontal membranda genişleme olmaması,

6. Kombine lezyonların dikkatlice incelenmesi,

7. Patolojik cebin olmaması,

8. Fistül olmaması,

9. Apikal hassasiyet olmaması,

10. Kökte perforasyon olmaması,

11. Aktif enfeksiyon olmaması gerekmektedir. ${ }^{5}$

Post-Kor Restorasyonlarının Endikasyonları:

1. Sabit ve hareketli protez ayağı olacak endodontik tedavi geçirmiş hasarlı dişlerde,

2. Köprü ayağı olacak aşııı malpoze dişlerde,

3. Overdenture protezlerde internal tutucu ataçman olarak uygulanacağı durumlarda,

4. Periodontal desteği azalmış dişlerde kron kök oranın dengelenmesi amacıyla,

5. Dişin kronunun $3 / 5^{\prime}$ inden fazlasının kaybı durumunda uygulanmaktadır. ${ }^{6,7}$

Post-Kor

Restorasyonların

\section{Kontrendikasyonları:}

1. İnce kök formunda kırılmaya meyilli dişlerde,

2. Periapikal patolojiler varlığında,

3. Endodontik tedavinin yetersiz olduğu durumlarda,

4. Kötü ağız hijyenine sahip hastalarda yapılması uygun değildir. 8,9

\section{Diş Hekimliğinde Postların Tarihi}

Geçmiş yıllardan beri kaybedilen diş yapısının tekrar nasıl yerine konacağı ile ilgili farklı uygulamalar denenmiştir. Talmud kalan diş kısmının korunması için köke destekleyici bir telin uygulanmasını önermiştir. ${ }^{4}$ Daha sonra Franklar, kalan diş kronunun desteklenmesi için tahta bir çivinin yerleştirilmesini tanımlamıştır. ${ }^{9}$ O yıllarda metal postların diş dokularına tutunmaları için uygun siman olmadığından tahtanın su emerek genleşmesinden dolayı daha retantif olduğu savunulmuştur. 1728 yllında bilimsel diş hekimliğinin başlamasıyla ilk olarak Fauchard kök kanallarına post uygulamasını tanımlamıştı. ${ }^{10}$

1830-1870 yıllarında post materyali olarak ahşap kullanılmışır. Daha sonra metal kullanıımaya başlanılmıştır. 1841'de Lefoulon kökün mum ile ölçüsünü alarak post uygulamasını yapmışıı. ${ }^{11} 1849$ ylında Sir John Tomes ilk defa post uzunluğu ve çapı ile ilgili bilgiler vermiştir. ${ }^{12}$

1950 yılında Uhlig günümüzde kullandığımız tekniğe benzer şekilde kök kanalını hazırlamış ve uygun materyalle restorasyonları yapmışır. ${ }^{13} 1967$ yilında Markley paslanmaz çelik pinlerle amalgamları kombine olarak kullanmışır. ${ }^{14}$

1968 yllında Colley ark. postların tutuculuk özelliklerini araştırmışlar ve tutuculuğun çap ve düzensizliklerle doğru orantılı olduğunu bulmuşlardır. ${ }^{9,10} 1978$ yllında Miller post-korlarda direk model tekniğini geliştirmiştir. ${ }^{11,12}$

İdeal Bir Postta Bulunması Gereken

\section{Özellikler}

1. Dişe minimal stres iletmeli,

2. Kor yapısı için yeterli tutuculuk sağlamalı,

3. Endodontik tedaviyi yenilemek gerektiğinde kanaldan kolayca uzaklaştırılabilmeli,

4. Kanal şekline uygun olmalı,

5. Minimum preparasyonla uygulanabilmeli,

6. Kanal duvarıyla arasında ince ve eşit miktarda siman kalınlığına izin vermeli,

7. Farklı uzunluk ve çapta tipleri bulunmalı,

8. Diş dokularına benzer biyomekanik özelliklere sahip olmall,

9. Termal genleşme katsayısı dentininkine yakın olmali,

10. Estetik özellikleri sonuç restorasyon ve çevre dokularla uyumlu olmalıdır. ${ }^{15-17}$

\section{Dental Postların Sınıflandırılması}

Post Şekillerine Göre:

1. Konik

2. Silindir

Tutuculuk Şekillerine Göre:

1. Aktif: Yivlerin dentin yüzeyine teması ile tutuculuğu sağlayan postlardır.

2. Pasif: Kanal formuna uygun olacak şekilde ancak kanal duvarlarına teması yapışııııı ajanlarla olan postlardır

Yapım Şekillerine Göre:

1. Fabrikasyon

2. Döküm

Kullanılan Materyallere Göre:

1. Metal alaşım postlar (Ti, Au-Pt, Paslanmaz çelik, $\mathrm{Pd}-\mathrm{Pt}-\mathrm{Cu}, \mathrm{Cr}-\mathrm{Ni}$, Amalgam)

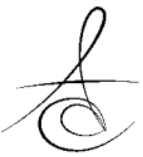


Atatürk Üniv. Diş Hek. Fak. Derg.

J Dent Fac Atatürk Uni

Cilt:29, Sayı:3, Yıl: 2019, Sayfa, 519-525

2. Seramik postlar
a. Cam seramik postlar
b. Aliminyum oksit ile güçlendirilmiş seramik postlar
c. Freze tekniği ile elde edilen seramik postlar
d. Zirkonyum esaslı seramik postlar

3. Fiber Postlar
i. Karbon fiber postlar
ii. Polietilen fiber postlar
iii. Cam fiber postlar
iv. Kuartz fiber postlar. ${ }^{9}$

\section{Dental Fiber Postlar}

Diş hekimliğinde, oklüzal kuvvetlere karşı koyabilecek, estetik beklentileri karşılayabilecek, uygulama kolaylığı sağlayan, kullanım ömrü uzun, ağız ortamına uyumlu ideal materyal arayışı, araştırmacıları rutin kullanılan materyallerin haricinde yeni materyaller aramaya sevk etmiştir. Bu araştırmalar sonucunda 'hafif, gerilme kuvvetlerine karşı çok güçlü' bir materyal olan fiberden faydalanılması düşünülmüştür. ${ }^{8}$

İlk üretilen fiber postlar paralel kenarlıdır ve araştırmacılar tarafından 'Prostetik' olarak tanımlanmıştır. Burada postun stabilizasyonu özel frezlerle hazırlanan yuva sayesinde sağlanmaktadır. Ancak kökün anatomik formuna uymasında yaşanan zorluk ve fazla miktarda doku kaybına neden olması bu postlardan vazgeçilmesine sebep olmuştur. Kanalların konik formda olması ve kanalları prepare etmek için kullanılan kanal aletlerinin de konik olması konik postların geliştirilmesini sağlamıştır. Bu tip postlara da 'Endodontik' postlar denilmiştir. Bunlar International Organization for Standartizasyon (ISO) standartlarına göre 90, 100, 120 no' lu aletlere uyacak şekilde yapılmıştır. Bu postlar prepare edilen kanala uygun olduğu için çok az bir preparasyonla yerleştirilebilir. Bunun yanı sıra köklerin morfolojik yapılarına uymaları her türlü kökte özelikle çok kısa ve çok dar köklerde de rahatıkla kullanılabilmelerini sağlamıştır. Ancak yapılan klinik çalışmalar endodontik tedavi yapılmış kanallarda homojen bir koniklik yerine koronal bölgede daha geniş, apikal bölgede daha dar olan konik form olduğu gözlenmiştir. Bu da 'Double taper' denilen iki farklı açıda konikleştirilmiş postların geliştirilmesini sağlamıştır. ${ }^{18-22}$

Günümüzde mevcut fiber postlar aslında kompozit materyallerdir. Bunlar bir polimer rezin matriks tarafından çevrelenmiş karbon, kuartz, zirkonyum, cam veya silika fiberlerden oluşur. Bu polimer rezin matriks genellikle epoksi rezindir. Fiber lifleri ve matriks bağlantısı için bağlayıcı ajan olarak silan kullanılmaktadır. Post sistemleri içindeki fiber oranı yaklaşık \% 35-65 arasındadır ve yüksek fiber içeriğine sahip olan post tipik olarak daha sert ve dayanıklıdır. ${ }^{23-25}$

Fiber postlar özel bir kompozit materyal içine gömülmüş fiber demetleri içerir. Bu demetler içinde fiberler multi-aksiyel olarak yerleşmiş örgü formunda ve epoksi rezinle güçlendirilmiş olarak bulunur. Farklı akslarda örgü formda düzenlenmiş fiberler paralel olarak düzenlenmiş olanlara oranla daha iyi eğilme ve burkulma direnci gösterirler. Matriks yapı ise poliamid, polyester, poliolefin, polimid, poliarilat, poliüretan, vinil esterler veya epoksi temelli polimer materyallerden üretilir. Polimer yapıda tercih edilen monomerler, bisfenol A-Glisidil metakrilat (BIS-GMA), poliüretan dimetakrilat (PUDMA), trietilen glikol dimetakrilat (TEDGMA), polietilen glikol dimetakrilat (PEGDMA), üretan dimetakrilat (UDMA), heksandiol dimetakrilat (HDDMA), polikarbonat dimetakrilat (PCDMA)'dir. Polimer matriksler, görülebilir ışıkla sertleşen, kendiliğinden sertleşen ve dual sertleşen tipte olabilir. Polimer matrikse, polimerizasyon hızlandırıcıları, polimerizasyon başlatıcıları, ultraviyole ışık emiciler, anti-oksidanlar, baryum sülfat radyoopak ajanlar eklenebilir. Matriks içine miktarı özel belirlenen quartz baryum silikat, baryum sülfat, baryum borosilikat, amorf silika, kalsiyum fosfat, alumina, zirkona gibi doldurucular eklenebilir. ${ }^{14,26,27}$

Adeziv dişhekimliğindeki olumlu gelişmeler ile yeni jenerasyon dentin bonding ajanlar rezin simanlar ve restoratif materyallerin ortaya çıkarılması endodontik tedavili dişlerin restorasyonunda fiber postların kullanımını yayınlaştırmıştır. ${ }^{27}$

\section{Fiber Postun Özellikleri:}

I. Dentine benzer elastik modülüne sahiptir. Böylece eşit derecede esneyerek üzerindeki restorasyonun kırılma direncini artırır.

II. Oklüzal stresleri dağıtır, metal post gibi direkt iletmez.

III. Fiber postlarda aktif yivler yerine pasif retansiyon olukları vardır. Kanala pasif olarak yerleştirildiğinden ve kanal duvarı ile post arasında yapıştırıcı ajan aracılığıyla bir hibridizasyon olduğundan kök üzerinde stres oluşmamaktadır.

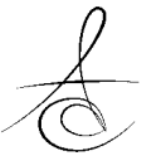


IV. Kompozit ve tam seramik restorasyonlar ile kullanımı uygundur.

V. Estetiktirler.

VI. Güncel adezivler ve kompozitlerle kimyasal olarak uyumludurlar.

VII. Kök kanalından çıkarılması gerektiğinde işlem özel frezler yardımıyla kolaylıkla yapılabilmektedir. ${ }^{27-30}$

Metal döküm postlar fiber postlara oranla oldukça rijittirler. Yüksek rijitlikte ki metal, gelen kuvvetleri hiçbir distorsiyona uğramadan alttaki daha az rijit olan dentine iletir ki; bu da hasara yol açabilir. Fiber ile güçlendirilmiş postlar, homojen olmayan yapıdadırlar ve kuvvetler karşısında bükülmektedirler. Bu sayede post ve dentin arasında streslerin dağılmasına neden olmaktadırlar. ${ }^{26,29}$

\section{Karbon Fiber Postlar}

Geliştirilen ilk metal olmayan post sistemidir. Karbon fiber postların baskı dayanımı 440 MPa, makaslama dayanımı $170 \mathrm{MPa}$, elastik modulüsü ise ortalama 17 GPa'dır. Bu özellikleri nedeniyle de diş dokusunda daha az gerilime neden oldukları bildirilmiştir. Karbon fiber post 1960 yılları başında üretilmiştir ve diş hekimliğinde 1970'lerin başında kullanılmaya başlanılmıştır. Karbon fiberler 19. yüzyılın sonlarında ince bambu filizlerinin karbonize edilmesiyle bulunmuştur. Karbon fiberlerin kullanımı 1971 'de Schreiber tarafından denenmiş, akriliğin çarpma dayanıklıı̆ı̆ını \%50 artırdığı görülmüştür. Karbon fiber, 200-250 derecede, daha sonra 1200 derece durağan atmosferde ısıtılan poliakrilonitrat'tan yapılır. Bu işlemde karbon atom zincirleri bırakılarak hidrojen, nitrojen ve oksijen uzaklaşır ve böylece karbon fibriller oluşur. Karbon fiber post ile restore edilen dişlere gelen kuvvetler post ve kor tarafından absorbe edilmekte ve böylelikle de kuvvetler geride kalan diş dokusuna iletilmemektedir. Karbon fiber postların, paslanmaz çelik postlarla kıyaslandığında daha az dikey kök kırığına neden olduğu bildirilmiştir. Titanyum ve krom-nikel postlara oranla köke daha az stres iletirler. Bükülmeye ve eğilmeye karşı dirençlidir. Karbon postlar radyografide radyolusent görüntü verirler. İncelenen örneklerde cilt irritasyonunun geliştiği bazı problemler yaşanmıştır. 1980'den sonra karbon fiber kullanımı oldukça azalmıştır Bunun nedeni;

1- Fiberin işlenmesinin zor olması,

2- Rezin içine fiberin tam olarak yerleştirilememesi,

3- Protez kaidesi ile fiber birleşim yerlerinde cilalama ile ilgili problemler,

4- Renginden dolayı kötü estetik, karbonun potansiyel toksisitesi ve güçlendirmeye alternatif metotların geliştirilmesi sayılmaktadır. ${ }^{30,31}$

Karbon fiber postların renklerinin siyah olması, karbon quartz fiber postların yapılmasına neden olmuştur. Günümüzde çeşitli ticari isimler altında karbon fiberle güçlendirilmiş post sistemleri mevcuttur. Composipost (RTD, Saint Egreve, Fransa), CF Carbon Fiber Post (J Morita, Irvine, Amerika), Cytec Blanco Carbon Fiber Post (Cytec Inc, Hahnenkratt, Almanya) bunlardan bir kısmıdır. ${ }^{32,33}$

\section{Polietilen Fiber Postlar}

Polietilen doğal polimer yapısıyla $0,97 \mathrm{~g} / \mathrm{cc}$

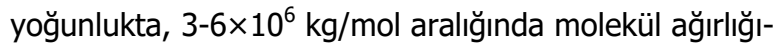
na sahip çizgisel homopolimer etilendir. Molekül ağırlığı $10 \times 10^{6} \mathrm{~kg} / \mathrm{mol}$ olduğu zaman yüksek molekül ağırlığına sahip polietilen olarak adlandırılırlar, düşük sürtünme katsayıları vardır, aşınmaya karşı dirençlidirler. Günümüzde, plazma ile güçlendirilmiş polietilen fiber materyali olarak Ribbond (Ribbond, Seattle, Wash; USA) bulunmaktadır. Örgü şerit şeklinde olan bu materyal kompozit rezin veya akrilik rezin ile birlikte kullanılmaktadır. Kristalin yapıda, dayanıklı, translusent, biyolojik olarak uyumlu, düşük yoğunluğa sahip olması, inert ve kırılgan olmaması ve kolayca uygulanabilmesi en önemli özellikleridir. Elastik modülü $60 \mathrm{GPa}$ değerindedir. Materyalin kullanım alanları, endodontik post ve korların yapımı, periodontal splintleme, direkt adeziv köprü protezlerinin yapımı, ortodontik tutucu olarak kullanımı, kompozit rezin restorasyon ve overdenture protezlerin güçlendirilmesi ve kırılmış köprü ve protezlerin tamir edilmesi olarak bildirilmiştir. ${ }^{26,29,30,33}$

Eklendikleri rezinin rengini yansıtırlar yani translusentirler. Estetiktirler, elastik modülü dentine yakındır. Tekrarlayan mekanik yüklemelerde ve nem ile temasta yapısı bozulmakta, elastik modulu azalmakta ve buna bağlı olarak bağlantı başarısızlığı meydana gelebilmektedir. ${ }^{30}$

\section{Cam Fiber Postlar}

Cam fiberler 1990'ı yılların ortasından beri diş hekimliğinde yaygın olarak kullanılmaktadır. Cam fiber materyalleri ilk olarak hareketli protez kaidesini ve ortodontik apareylerin yapısını güçlendirmek amacıyla kullanılmıştır. Daha sonraları splintleme amacıyla periodontoloji, ortodonti ve pedodonti alanlarında kullanılmış ve birçok vakada tedaviler sunulmuştur. Protetik uygulamalarda ise protez kaidesini güçlendirmeye 
ilaveten, yüzey tutuculu inley veya adeziv kombine köprü yapımında, geçici akrilik protezlerin yapısını güçlendirmek amacıyla, implant destekli protezlerde üst yapı hazırlanmasında ve kanal içi endodontik post yapımında kullanılmaktadır. 30,31,33

Cam fiberler; örgü, dağınık veya tek yönlü devamlı şekilde fiber paketlerinden oluşan ve dental polimerleri güçlendiren farklı yapılardaki materyallerden oluşmaktadır. Tek yönlü cam fiberler 1000-200.000 tek cam fiberin bir araya gelmesiyle oluşmaktadır. ${ }^{32}$

Primer cam yapıcı materyaller silisyum oksit, boroksit, germanyum oksit, fosfor oksit ve arsenik oksit gibi oksitlerden oluşmaktadır. Bu oksitler başka bir okside intiyaç duymadan cam yapabilmektedir. En sık kullanılan cam yapıcı oksit ana maddesi \% 70-72 silisyum olan, soğutulmuş alkali ve toprak alkali metal oksitleriyle, bazı metal oksitlerin çözülmesinden oluşmaktadır. Yoğunluğu 2,55 g/cc, elastik modulu 6873 GPa'dır. Cam fiberler, genellikle eritme-bükme teknikleri ile üretilmektedir. Bu teknikte, erimiş camın akması için küçük delikleri olan platin tacın içine cam bileşimi eritilmektedir. Devamlı fiberler deliklerden çekilmekte ve iğler halinde sarılmakta, fiberler daha sonra fiziksel yollarla veya hava jetleri ile istenilen uzunluklarda kesilmektedirler. ${ }^{32-35}$

Günümüzde 5 farklı tipte cam, fiber yapımında kullanılmaktadır ve isimlerini karakteristik özelliklerinden almaktadırlar. A-cam, \%25 oranında soda ve kireç içeren yüksek alkali camdır, kimyasal maddelere karşı dirençlidir ve düşük elektriksel özellik göstermektedir. C-cam, yüksek kimyasal dirence sahip bir kimyasal camdır. E-cam, düşük alkali içeriğine sahip bir elektriksel yapıdır. İyi bir elektrik yalıtkanıdır ve neme karşı dirençlidir. Güçlendirmede kullanılan cam fiberlerin \%50'si E-cam fiberdir. S-cam (yüksek dayanıklı cam) da amorf yapıda olup \%65 $\mathrm{SiO}_{2}, \% 25 \mathrm{Al}_{2} \mathrm{O}_{3}, \% 10 \mathrm{MgO}$ içermektedir. Gerilim dayanımı, E-cam fiberin yaklaşık olarak iki katıdır ve daha serttir. D-cam, üstün elektriksel özelliklere sahiptir. Ancak, mekanik özellikleri E-cam ve S-cam kadar yeterli değildir. ${ }^{36-38}$

Cam fiberler yanmaz, inhalasyonları düşüktür, ancak solunum sisteminde irritasyona sebep olabilirler. Sindirim sisteminde toksik etkisi vardır, gözler ve deri için irritandırlar. Akrilik rezinlerin güçlendirilmesinde en çok kullanılan fiber, cam fiberdir. Günümüzde çeşitli ticari isimler altında cam fiberle güçlendirilmiş post sistemleri mevcuttur. Cytec Blanco (Cytec Inc., Hahnenkratt, Almanya), Luscent Anchors (Dentatus,
Hagersten, İsveç) ve Snow post (Carbotech, Ganges, Frances) cam fiberle güçlendirilmiş postlardan bazılarıdır. ${ }^{39-43}$

Elastik modulu dentine benzerdir. Cam postlar estetiktirler, kompozit ve tam seramik restorasyonlar ile kullanımı uygundur. Cam fiber postların rezin simanlarla bağlanma dayanıklıı̆̆ı yüksektir. ${ }^{44-46}$ Işık geçişine izin vermektedirler. Dentine benzer bükülme dayanımına sahiptir ve stresleri geniş yüzey alanlarına dağıtırlar. Renksizliği ve doku uyumu gibi avantajları sayesinde tercih edilirler. ${ }^{47-50}$

\section{Kuartz Fiber Postlar}

İlk defa 1998 yılında Recherches Techniques Dentaires (RTD) firması tarafından Aestheti Plus ticari ismiyle geliştirilmiştir. Daha sonra firma 1999 yılından itibaren sırasıyla Light post, DT White post ve DT Light post adı altında farklı şekillerde kuartz fiber postları üretmiştir. Kuartz fiber postlar, $8 \mu \mathrm{m}$ çapında kuartz fiber liflerinden oluşmaktadırlar. Kuartz fiberler epoksi reçine matriks içerisine gömülmüştür ve içeriklerinde baryum bulunmaktadır. Mikroporöz yüzey özelliği göstermektedirler. Birim yüzey alanına düşen fiber liflerinin fazla olması nedeniyle, cam fiber postlara kıyasla daha yüksek çekme direnci, cam fiber ve zirkonyum postlara nazaran daha yüksek kırılma direncine sahiptir. Dentine benzer elastik modulleri sayesinde restorasyona gelen kuvvetler eşit bir şekilde dentin dokusuna iletilmekte ve restorasyon ara yüzünde stres oluşumu önlenmektedir. ${ }^{50-54}$

Zuhal Görüş: 0000-0003-1114-3333

Ayșe Meșe: 0000-0002-1612-5516

O.Erdost Evran: 0000-0003-1187-5235

Merve Tokgöz Çetindağ: 0000-0002-1330-8026

\section{KAYNAKLAR}

1- Assif D, Gorfil C. Biomechanical considerations in restoring endodontically treated teeth. J Prosthet Dent. 1994; 71: 565-7.

2- Sedgley $\mathrm{CM}$, Messer $\mathrm{HH}$. Are endodontically treated teeth more brittle? J Endod. 1992; 18: 332-5.

3- Jacobi R, Shillingburg HT. Pins, dowels, and other retentive devices in posterior teeth. Dent Clim North Am. 1993; 37: 367-90.

4- Cheung W. A review of the management of endodontically treated teeth. Post core and the final restoration. J Am Dent Assoc. 2005; 136: 611-9. 
Atatürk Üniv. Diş Hek. Fak. Derg.

J Dent Fac Atatürk Uni

Cilt:29, Sayı:3, Yıl: 2019, Sayfa, 519-525

5- Saupe WA, Gluskin AH, Radke RA Jr. A comparative study of fracture resistance between morphologic dowel and cores and a resinreinforced dowel system in the intraradicular restoration of structurally compromised roots. Int Quintessence. 1996; 27: 483-91.

6- Weichman JA, Johnson FM. Laser use in endodontics. A preliminary investigation. Oral Surg Oral Med Oral Pathol. 1971; 31: 416-20.

7- Ishikawa I, Aoki A, Watanabe H. Erbium:YAG laser, promising procedure for caries treatment. Dent Japan 1997; 33: 165-9.

8- Schwartz RS, Robbins JW. Post placement and restoration of endodontically treated teeth: a literature review. J Endod. 2004; 30: 289-301.

9- Strassler HE, Cloutier PC. A new fiber post for esthetic dentistry. Compend Contin Educ Dent. 2003; 24: 742-4.

10-Vichi A, Grandini S, Davidson CL, Ferrari M. An SEM evaluation of several adhesive systems for bonding fiber posts under clinical conditions. Dent Mater. 2002; 18: 495-502.

11-Bateman G, Ricketts DNJ, Saunders WP. Fibrebased post systems: a review of the literature. J British Dent. 2003; 195: 43-8.

12-Chan FW, Harcourt JK, Brockhurst PJ. The effect of post adaptation in the root canal on retention of posts cemented with various cements. J Australian Dent. 1993; 38: 39-45.

13-Boschian PL, Cavalli G, Bertani P, Gagliani M. Adhesive post endodontic restorations with fiber posts: push out tests and SEM obervations. Dent Mater. 2002; 18: 596-602.

14- Grandini S, Goracci C, Tay FR, Grandini R, Ferrari $M$. Clinical evaluation of the use of fiber posts and direct resin restorations for endodontically treated teeth. J Int Prosthet. 2005; 18: 399-404.

15-Yoldas O, Akova T, Uysal H. An experimental analysis of stresses in simulated flared root canals subjected to various post-core applications. J Oral Rehabil. 2005; 32: 427-32.

16-Ottl $\mathrm{P}$, Lauer $\mathrm{HCH}$, Fay $\mathrm{M}$. Fracture charasteristics of carbon fibre, ceramic and non palladium endodontic post systems at monotonously incrasing loads. J Oral Rehabil. 2002; 29: 175-83.

17-Nicolas C. Mechanical properties of glass fiberreinforced endodontic posts. Acta Biomat. 2009; 5: 3224-30.
18-Cagidiaco MC, Garcia-Godoy F, Vichi A, Grandini S, Goracci C, Ferrari M. Placement of fiber prefabricated or custom made posts affects the 3year survival of endodontically treated premolars. J Am Dent. 2008; 21: 179-84.

19-Fernandes AS, Dessai GS. Factors affecting the fracture resistance of postcore reconstructed teeth: A review. Int J Prosthet. 2001; 14: 355-63.

20-Fernandes AS, Shetty $S$, Coutinho I. Factors determining post selection: a literature review. J Prosthet Dent. 2003; 6: 556-62.

21-Çuhadaroğlu MI. Kron köprü protezi. 3. Baskı, Ankara: 1977.

22-Yaman SD, Alaçam T, Yaman Y. Analysis of stress distribution in a maxillary central incisor subjected to various post and core applications. J Endod. 1998; 24: 107-11.

23-Christensen GJ. Post and cores. J Am Assoc Dent. 1998; 129: 96-7.

24-Koutayas SO, Kern M. All-ceramic posts and cores: the state of the art. Int Quint. 1999; 6: 383-92.

25- Assif D, Gorfil C. Biomechanical considerations in restoring endodontically treated teeth. J Prosthet Dent. 1994; 6: 565-7.

26-Trabert KC, Cooney JP. Endodontically treated tooth restorative concepts and techniques. Dent Clin North Am. 1994; 28: 923-51.

27-Tait CME, Ricketts DNJ, Higgins AJ. Weakened anterior roots intraradicular rehabilitation. $\mathrm{J} \mathrm{Br}$ Dent. 2005; 198: 609-17.

28-Aksornmuang J, Foxton RM, Nakajima M, Tagami J. Microtensile bond strength of a dual cure resin core material to glass and quartz fiber posts. J Dent. 2004; 32: 443-50.

29-Toksavul S, Tornan M, Uyulgan B, Schmage P, Nergiz I. Effect of luting agents and recontruction techniques on the fracture resistance of prefabricated post systems. J Oral Rehabil. 2005; 32: 433-40.

30-Sadek FT, Goracci C, Monticelli F, Grandini S, Cury AH, Tayf F, Ferrari M. Immediate and 24 hour evaluation of the interfacial strengths of fiber posts. J Endod. 2006; 32: 1174-7.

31-Sirimal S, Riis DN, Morgano SM. An in vitro study of the fracture resistance and incidence of vertical root fracture of pulpless teeth restored with six post and core systems. J Prosthet Dent. 1999; 81: 262-9. 
32-Keyf F. Aşırı madde kaybına uğramış dişlerin protetik onarımı: Post-core sistemlerinin retantif özellikleri. Gazi Ünv Diş Hek Fak Derg. 1992; 9: 209-21.

33-Pest B, Cavalli G, Bertani P, Gagliani M. Adhesive post-endodontic restorations with posts: Push-out test and SEM observations. Dent Mater. 2002; 18: 596-602.

34-Gesi A, Magnolfi S, Goracci C, Ferrari M. Comparison of two techniques for removing fiber posts. J Endod. 2003; 29: 580-2.

35-Akan H, Kesim B. Üç farklı post-core sisteminin sıkışma kesme testlerine dayanımlarının in vitro olarak incelenmesi. Cumhuriyet Üni Diş Hek Fak Derg. 2000; 3: 31-7.

36-Bateman G, Ricketts DNJ, Saunders WP. Fibrebased post systems: a review. Br Dent J. 2003; 195: 43-8.

37-Naumann M, Blankenstein F, Dietrich T. Survival of glass fibre reinforced composite post restorations after 2 years-an observational clinical study. J Dent. 2005; 33: 305-12.

38-Naumann M, Sterzenbac G, Alexandra F, Dietrich T. Randomized controlled clinical pilot trial of titanium glass fiber prefabricated posts: preliminary results after up to 3 years. Int J Prosthodont. 2007; 24: 967-77.

39-Kıvanç BH. Endodontik tedavili dişlerde post uygulamaları. Atatürk Üni Diş Hek Fak Derg 2006; 2: $18-23$.

40- Giovana MG, Osnara MG, Allessandra R, Joao CG, Abraham LC. Regional bond strengths to root canal dentin of fiber posts luted with three cementation systems. J Braz Dent. 2011; 6: 22.

41-Çökük N. Endodontik tedavili dişlerde estetik post sistemleri. Atatürk Üni Diş Hek Fak Derg. 2009; 18; 208-16.

42-Pegoretti A, Fambri L, Zappini G, Bianchetti M. Finite element analysis of a glass fibre reinforced composite endodontic post. Biomaterials. 2002; 23: 2667-82.

43-Boschian Pest L, Cavalli G, Bertani P, Gagliani M. Adhesive post-endodontic restorations with fiberposts: push-out tests and SEM observations. Dent Mater. 2002; 18: 596-602.

44-Vichi A, Grandini S, Ferrari M. Clinical procedure for luting glass-fiber posts. J Adhes Dent. 2001; 3: 353-9.
45-Schmage P, Pfeiffer P, Pinto E, Platzer U, Nergiz I. Influence of oversized dowel space preparation on the bond strengths of FRC posts. Oper Dent. 2009; 34: 93-101.

46-Akman M,Akman S,Kalkan M. Endodontik postlarda yenilikler. Selçuk Üni Diş Hek Fak Derg. 2006; 15: 155-60.

47-Ayaz F, Tağtekin D, Yanıkoğlu F. Dentine bağlanma ve değerlendirme metodları. Atatürk Üni Diş Hek Fak Derg. 2011; 4: 49-56.

48-Ferrari M, Vichi A, Grandini S, Goracci C. Efficacy of a self-curing adhesive resin cement system on luting glass-fiber posts into root canals: an SEM investigation. Int J Prosthodont 2001; 14: 543-9.

49-Goracci C, Corciolani G, Vichi A, Ferrari M. Light transmitting ability of marketed fiber posts. J Dent Rest. 2008; 87: 1122-6.

50-Mallmann A, Jacques LB, Valandro LF, Muench A. Microtensile bond strength of photoactivated and autopolymerized adhesive systems to root dentin using translucent and opaque fiber-reinforced composite posts. J Prosthet Dent. 2007; 97: 16572.

51-Kececi AD, Ureyen Kaya B, Adanir N. Micro pushout bond strengths of four fiber-reinforced composite post systems and two luting materials. Oral Surg Oral Med Oral Pathol Oral Radiol. 2008; 105: 121-8.

52-Goracci C, Ferrari M. Current perspectives on post systems: a literature review. J Australian Dent. 2011; 56: 77-83.

53-Helvacıoğlu B. Endodontik tedavili dişlerde post uygulamaları. Atatürk Üni Diş Hek Fak Derg. 2006; 12: 18-23.

54-Spazzin AO, Moraes RR, Cecchin D, Farina AP, Carlini-Ju 'nior B, Correr-Sobrinho L. Morphological analysis of glass, carbon and glass-carbon fiber posts and bonding to self or dual-cured resin luting agents. J Appl Oral Sci. 2009; 17: 476-80.

\author{
Yazışma Adresi \\ Ayşe MEŞE \\ Dicle Üniversitesi Diş Hekimliği Fakültesi \\ Protetik Diş Tedavisi Anabilim Dalı/DİYARBAKIR \\ Tel: 0412-2488101-05054845819 \\ Fax: 0412-2488100 \\ Email: aysemese@yahoo.com
}

